\title{
Study of Outcomes of Desarda Repair in Emergency Conditions of Inguinal Hernia
}

\author{
Mohamed Salah Abdel-Kader*, Wesam Mohammed Ali, Hany Mohamed, Sherif Mohammed Holiel \\ Department of General Surgery, Faculty of Medicine, Zagazig University, Egypt \\ *Corresponding author: Mohamed Salah Abdel-Kader, E-Mail: mohamedsalahalhosary906@ gmail.com
}

\begin{abstract}
Background There are two types of hernias in men and women: inguinal hernias and abdominal hernias. Inguinal hernias can be treated with the Desarda technique, a suture-based procedure that is becoming more popular. Objective: improving inguinal hernia repair outcomes by avoiding complications caused by foreign bodies.

Patients and Methods: 40 male patients with difficult inguinal hernias were studied in the General Surgery Department of the Faculty of Medicine, Zagazig University Hospital, as part of a prospective study. Six months of follow-up took place from September 2020 to November 2021. Experienced and trained surgeons performed Desarda method procedures on patients. Pain and gait were measured at each follow-up.

Results: Twenty-seven of the studied patients had no postoperative complications. Wound infection, seroma and scrotal edema occurred in 5,6 and 2 of the patients respectively. A statistically significant difference in postoperative Visual Analogue Scale (VAS) scores was found between the groups tested (significantly higher among strangulated hernia). In terms of postoperative complications, the two groups analyzed differ significantly. In cases with obstructed hernia, non-complicated hernias accounted for 23, while strangulated hernias accounted for four. Conclusion: The Desarda approach appears to be a viable alternative to current practices. There are no problems or hernia recurrences as a result of this procedure, which is rapid, uncomplicated, and easy to learn and conduct.
\end{abstract}

Keywords: Desarda Repair, Inguinal Hernia

\section{INTRODUCTION}

Protrusion of a viscous or a component of a viscous through an irregular opening in the walls of its enclosing cavity is known as hernia ${ }^{(1)}$. The inguinal hernia is the most frequent hernia in both sexes; however, men are more likely to suffer from it. 27 percent of men and 3 percent of women have an inguinal hernia at some point in their lives ${ }^{(2)}$.

An inguinal hernia is a common occurrence in both the outpatient and emergency departments. As a result of its prevalence, it is still a significant medical issue. Groin hernias are most commonly caused by male gender and the ageing process ${ }^{(3)}$.

Desarda is a new suture-based surgery that is gaining popularity. A mesh-free, tension-free, and surgical physiology of the inguinal canal are the hallmarks of this surgery. Due to the use of more established methods, there is a lack of data to evaluate the effectiveness of this strategy ${ }^{(4)}$.

In the developed world, Lichtenstein repair is the most usual procedure. In spite of these drawbacks, Lichtenstein mesh repair has its advantages, including its low cost, availability in many developing countries, and ability to fold or wrinkle. Chronic groin sepsis that requires mesh removal is also a drawback. Many researchers are looking for innovative ways to heal hernias because of the observed risks and postoperative dysfunctions. The Desarda approach, which was introduced in 2001 and established a new surgical alternative for tissue-based groin hernia repair, is a good illustration of this effort ${ }^{(5)}$.
Prosthetic mesh is replaced with an external oblique aponeurosis strip to strengthen the posterior wall. It is simple, safe, tension-free, permanent, and does not use weaker muscle or transversalis fascia for restoration. The cost-effectiveness of treatment is an important consideration in the fight against the disease (6).

So, this study was carried out to examine the results of the Desarda method of inguinal hernia repair so as to improve the outcome of inguinal hernia repair by avoiding foreign body related complications.

\section{PATIENTS AND METHODS}

40 male patients of different types of complicated inguinal hernia at Zagazig University Hospitals between September 2020 and November 2021 served as the subjects for this prospective study.

\section{Ethical consent:}

An approval of the study was obtained from Zagazig University Academic and Ethical Committee (ZU-IRB\#6275). Surgical technique was explained for all the cases. Every patient signed an informed written consent for acceptance of the operation and participation in this study. This work has been carried out in accordance with The Code of Ethics of the World Medical Association (Declaration of Helsinki) for studies involving humans. 


\section{Inclusion criteria:}

People between the ages of 18 and 80 years old who had been diagnosed clinically with incarcerated, or strangulated inguinal hernias.

Exclusion criteria: Age: < 18 years, Complicated recurrent hernia, Class 4 and 5 according to physical status classification of the American Society of Anesthesiologists as well as patients who were unfit for the operation.

History: The patient's age, sex, gender, risk factors, history were all recorded in a thorough medical history.

\section{Clinical general and local examination. Laboratory evaluation:}

Routine preoperative investigations as full laboratory workup (including CBC, PT, PTT, INR, liver function tests and kidney function tests).

Evaluations of the operative time, hospital stay and any intraoperative complications.

Patients underwent Desarda technique, and surgeries were done by experienced and skilled surgeon.

After surgeries, complete postoperative treatment was started. Postoperative pain was assessed using visual analogue scale (VAS) with 0-30 mm signifying mild pain, 31-60 mm moderate pain, 61-90 severe pain and 91-100 excruciating pain.

All the patients were discharged on stabled conditions and all the postoperative complications were noted.

Postoperative follow-up was given twice hourly just after the operation and on first, second and third postoperative days, and then on seventh postoperative day. In each follow-up, pain was scored and gait was assessed.

\section{Surgical technique (Figures 1-4):}

Open skin and subcutaneous tissue. Cauterization and divide the 3 superficial veins (superficial epigastric, superficial circumflex vein and superficial external pudendal vein).

Divide the external oblique aponeuroses in the direction of its fibers extending till the internal ring. The upper and lower leaf was dissected and protect the ilioinguinal nerve.

The sac was dissected and excised. In cases of strangulated hernia resection of the gangrenous loop and anastomosis with intra-abdominal drain was done. Non-absorbable sutures (proline) were used to attach the upper leaf of external oblique aponeurosis (EOA) to the surface of the inguinal ligament by continuous sutures. Medial leaf of EOA, $1.5-2 \mathrm{~cm}$ wide, was cut $1.5-2 \mathrm{~cm}$ wide from the pubic symphysis and stretched medially. And a few centimetres to the side of the interior ring.

To preserve this strip's medial attachment and lateral extension, it was left intact. An interrupted suture was used to attach the upper free edge of the strip to the conjoint tendon with number 1 monofilament poly dioxanone violet (PDS). As a result, the EOA was put behind the cord to build a new inguinal canal wall.

It was put in the inguinal canal with the spermatic cord. A monofilament poly dioxanone violet (PDS) was used to suture the EOA's lateral leaf to the freshly produced medial leaf in front of the cord. If necessary, a suction drain was used.

After this, the skin and subcutaneous tissue were stitched shut.

\section{Postoperative follows up:}

They were followed up for 14 days for early postoperative complication until the sutures were removed and for one year for late postoperative complication as chronic pain and recurrence.

In the obstructed cases, when resection anastomosis was not done, were return to home the next morning, while in strangulated cases, they remained for 6-8 days until they take fluid and food without complications. 


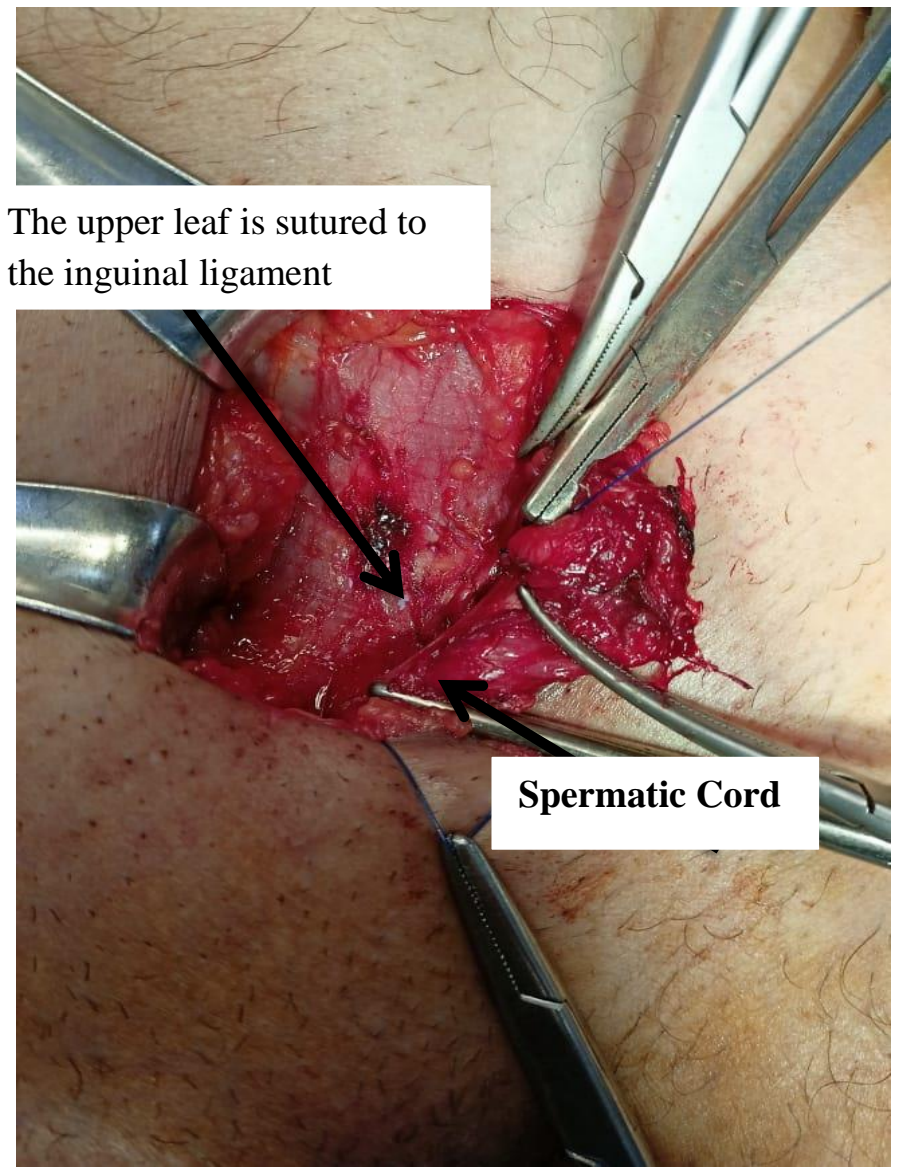

Figure (1): The upper leaf is sutured to the inguinal ligament

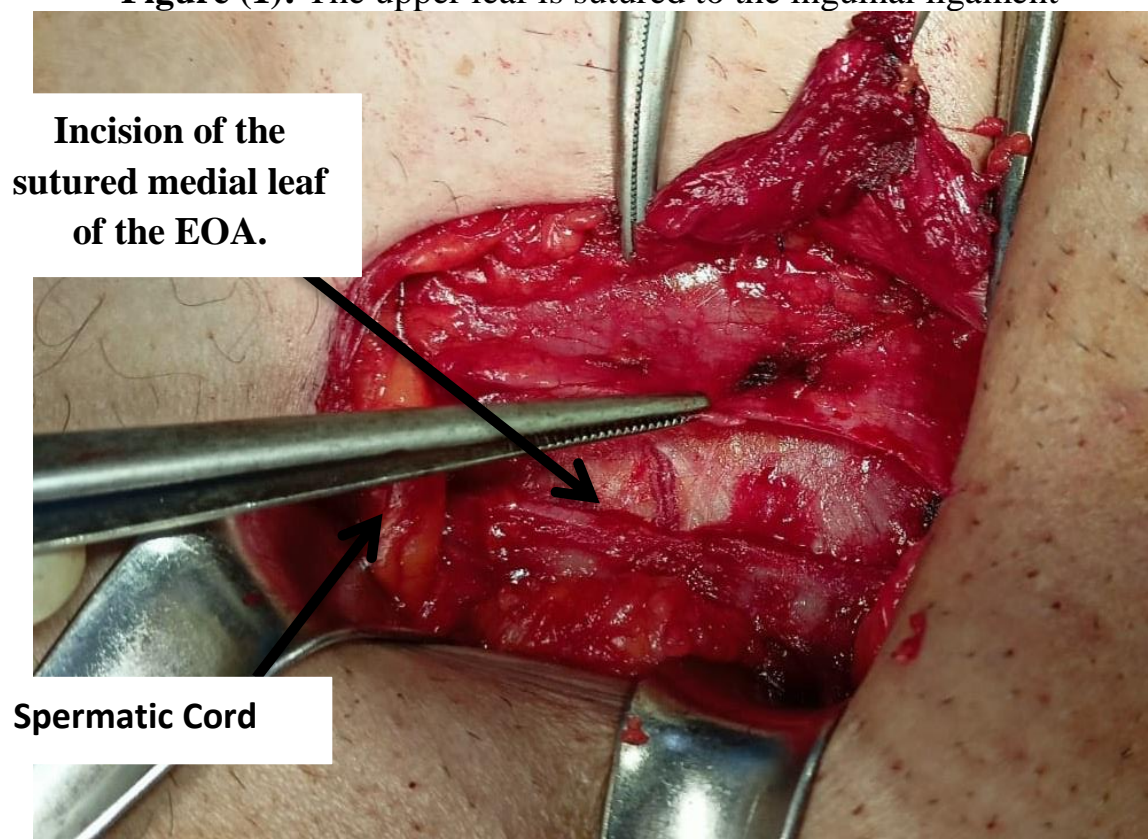

Figure (2): The strip is separated from the external oblique aponeurosis 


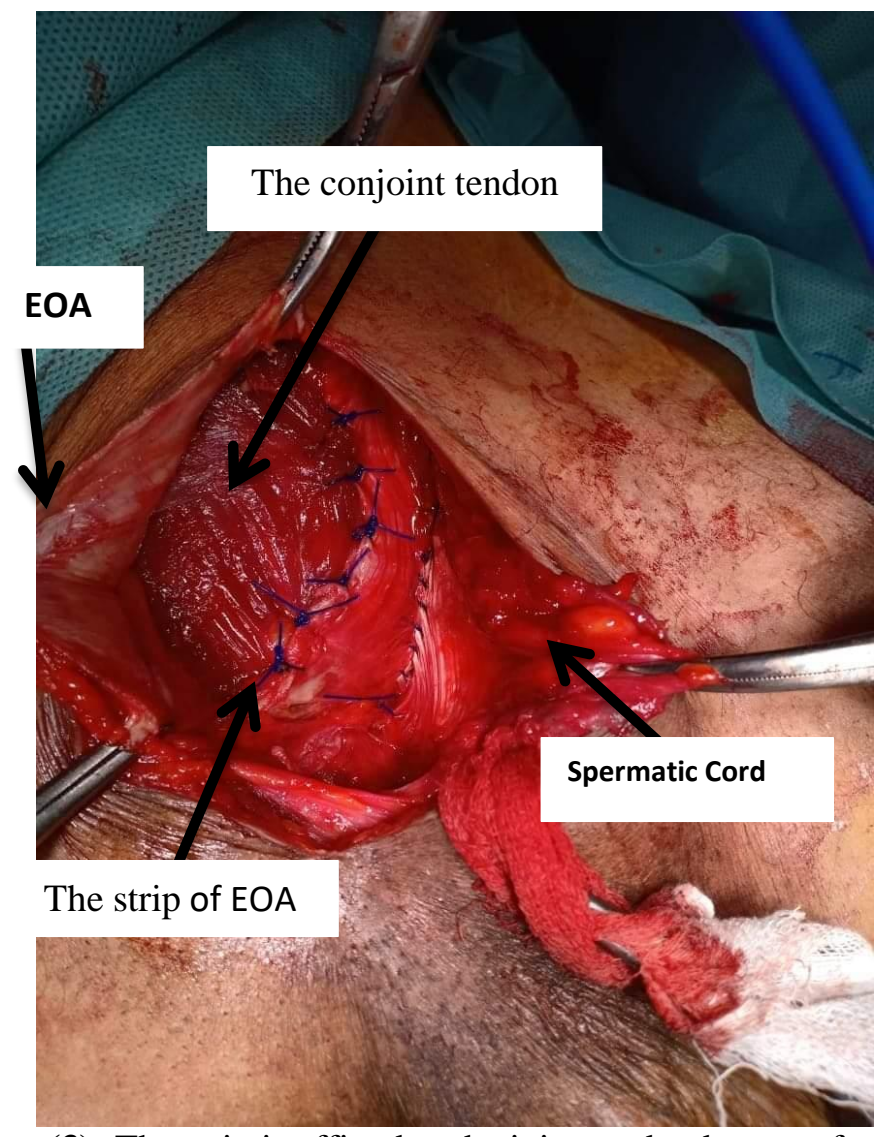

Figure (3): The strip is affixed to the joint tendon by use of a suture.

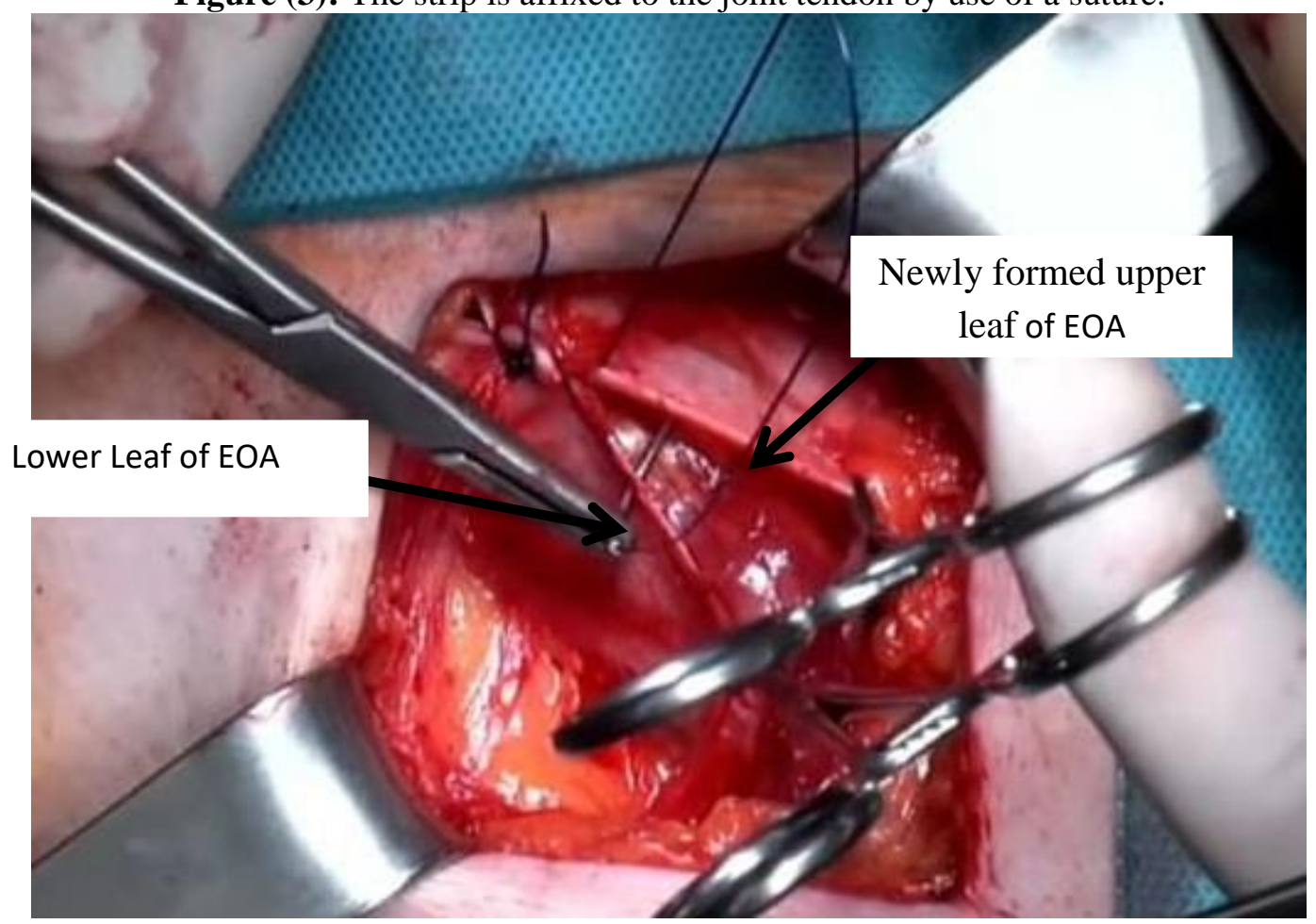

Figure (4): The lower leaf is sutured to newly formed upper leaf 


\section{Statistical analysis:}

Quantitative data were presented as mean \pm standard deviation (SD), median, and range. The independent t-test ( $\mathrm{t}$ ) and the Mann-Whitney (MW) tests were employed to compare parametric and nonparametric quantitative data, respectively.

Qualitative data were presented as frequency and proportions and were compared using Fisher's exact test $\left(\mathrm{X}^{2}\right)$. $\mathrm{P}$ value 0.05 was considered statistically significant. It was judged highly significant when the $P$ value was 0.001 .

\section{RESULTS}

Age of the studied patients ranged from 18 to 86 years with mean age 47.675 years. About $68 \%$ of the studied patients had no comorbidity (Table 1).

Table (1): Demographic and clinical data of the studied patients

\begin{tabular}{|l|c|c|}
\hline Gender: & $\mathbf{N}=\mathbf{4 0}$ & \% \\
\hline Male & 40 & 100 \\
\hline Age (year): & & \\
\hline Mean \pm SD & $47.675 \pm 17.022$ & \\
\hline Range & $18-86$ & \\
\hline Comorbidity: & 27 & $67.5 \%$ \\
\hline NAD & 1 & $2.5 \%$ \\
\hline COPD & 2 & $5 \%$ \\
\hline IHD & 3 & $12.5 \%$ \\
\hline Diabetes & 5 & $5 \%$ \\
\hline Hypertension & 2 & \\
\hline Diabetes and hypertension & & \\
\hline
\end{tabular}

27 of the studied patients had no postoperative complications (Table 2).

Table (2): Distribution of the studied patients according to postoperative complications

\begin{tabular}{|l|c|c|}
\hline \multicolumn{1}{|c|}{ Complications } & $\mathbf{N}=\mathbf{4 0}$ & \% \\
\hline No & & \\
\hline Wound infection & 27 & $67.5 \%$ \\
\hline Seroma & 5 & $12.5 \%$ \\
\hline Scrotal edema & 6 & $15 \%$ \\
\hline
\end{tabular}

There was statistically significant decrease in postoperative VAS pain score over time, which decreased from 4.275 two hours postop to 1 in the first postoperative week (Table 3). 
Table (3): Postoperative VAS score of the studied patients

\begin{tabular}{|l|c|}
\hline \multicolumn{1}{|c|}{ 2 hours postoperatively } & $\mathbf{N}=\mathbf{4 0}$ \\
\hline Mean \pm SD & $4.275 \pm 1.037$ \\
\hline Median & 4 \\
\hline Range) & $43-7$ \\
\hline $\mathbf{1}^{\text {St }}$ postoperative day: & $3.4 \pm 1.057$ \\
\hline Mean \pm SD & 3 \\
\hline Median & $2-6$ \\
\hline Range & $2.675 \pm 0.797$ \\
\hline 2 $^{\text {nd }}$ postoperative day: & 3 \\
\hline Mean \pm SD & $1-4$ \\
\hline Median & \\
\hline Range & $1.675 \pm 0.73$ \\
\hline 3rd postoperative day: & 2 \\
\hline Mean \pm SD & $1-3$ \\
\hline Median & \\
\hline Range & $0.65 \pm 0.622$ \\
\hline Seventh day & 1 \\
\hline Mean \pm SD & $0-2$ \\
\hline Median & $<0.001 * *$ \\
\hline Range & \\
\hline P (F) & \\
\hline
\end{tabular}

**: Highly significant

Study groups differ significantly in the amount of time it takes to perform surgery (longer in patients with strangulated hernia) (Table 4).

Table (4): Comparison between types of complicated hernia regarding operative time

\begin{tabular}{|l|c|c|c|}
\hline \multicolumn{1}{|c|}{ Parameter } & \multicolumn{2}{|c|}{ Complicated hernia } & \multirow{2}{*}{ P value } \\
\hline Operative time (minutes) & $\begin{array}{c}\text { Obstructed } \\
\mathbf{N}=\mathbf{3 0}\end{array}$ & $\begin{array}{c}\text { Strangulated } \\
\mathbf{N = 1 0}\end{array}$ & \\
\cline { 1 - 3 } \pm & $41.2 \pm 4.475$ & $53.0 \pm 13.581$ & \multirow{2}{*}{$\mathbf{0 . 0 0 1 *}$} \\
\hline Mean \pm SD & $35-60$ & $35-65$ & \\
\hline
\end{tabular}

\section{*: Significant}

Patients with strangulated hernia spend more time in the hospital and have a longer time to return to work than those without the condition (longer in patients with strangulated hernia). (Table 5).

Table (5) Comparison between types of complicated hernia regarding length of hospital stay and time to

\begin{tabular}{|c|c|c|c|}
\hline \multirow{2}{*}{ Parameter } & \multicolumn{2}{|c|}{ Complicated hernia } & \multirow[t]{2}{*}{$\mathbf{P}$} \\
\hline & $\begin{array}{c}\text { Obstructed } \\
\mathbf{N}=\mathbf{3 0}\end{array}$ & $\begin{array}{c}\text { Strangulated } \\
\mathbf{N}=\mathbf{1 0}\end{array}$ & \\
\hline $\begin{array}{l}\text { LOS (day): } \\
\text { Mean } \pm \text { SD } \\
\text { Range }\end{array}$ & $\begin{array}{c}1.1 \pm 0.305 \\
1-2\end{array}$ & $\begin{array}{c}5.2 \pm 3.225 \\
1-7\end{array}$ & 0.001 \\
\hline $\begin{array}{l}\text { Return to work (day): } \\
\text { Mean } \pm \text { SD } \\
\text { Range }\end{array}$ & $\begin{array}{c}16.5 \pm 2.701 \\
12-20\end{array}$ & $\begin{array}{c}18.0 \pm 3.464 \\
14-21\end{array}$ & 0.001 \\
\hline
\end{tabular}

A statistically significant difference in postoperative VAS scores was found between the groups tested (significantly higher among strangulated hernia). On comparing percent change in VAS over time, VAS in obstructed hernia decreased by $303.57 \%$ while it decreased by $377.78 \%$ in strangulated hernia with a statistically non-significant difference (Table 6). 
Table (6): Comparison between types of complicated hernia regarding postoperative VAS

\begin{tabular}{|c|c|c|c|}
\hline Parameter & $\begin{array}{c}\text { Complicated herniaObstructed } \\
\mathrm{N}=\mathbf{3 0}\end{array}$ & $\begin{array}{c}\text { Strangulated } \\
\mathbf{N}=10\end{array}$ & $\mathbf{P}$ \\
\hline \multicolumn{4}{|c|}{2 hours postoperatively: } \\
\hline Mean \pm SD & $4.067 \pm 0.785$ & $4.2 \pm 1.687$ & \multirow[t]{2}{*}{ 0.001* } \\
\hline Rang & $3-5$ & $3-7$ & \\
\hline \multicolumn{4}{|c|}{ 1 ${ }^{\text {st }}$ postoperative day: } \\
\hline Mean \pm SD & $3.133 \pm 0.819$ & $4.5 \pm 1.08$ & \multirow[t]{2}{*}{$0.001 *$} \\
\hline Median (Range) & $2-4$ & $2-6$ & \\
\hline \multicolumn{4}{|c|}{ 2nd postoperative day: } \\
\hline Mean \pm SD & $2.567 \pm 0.774$ & $2.4 \pm 2.066$ & \multirow[t]{2}{*}{ 0.001* } \\
\hline Median (Range) & $2(2-4)$ & $3.5(1-4)$ & \\
\hline \multicolumn{4}{|c|}{$3^{\text {rd }}$ postoperative day: } \\
\hline Mean \pm SD & $1.567 \pm 0.774$ & $1.8 \pm 1.814$ & \multirow[t]{2}{*}{ 0.001* } \\
\hline Median (Range) & $1(1-3)$ & $2(1-3)$ & \\
\hline \multicolumn{4}{|l|}{ Seventh day: } \\
\hline Mean \pm SD & $0.7 \pm 0.837$ & $1.4 \pm 1.955$ & \multirow[t]{2}{*}{ 0.001* } \\
\hline $\begin{array}{l}\text { Median (Range) } \\
\mathbf{P}(\mathbf{F})\end{array}$ & $\begin{array}{l}0(0-2) \\
<0.001 * *\end{array}$ & $\begin{array}{l}1(0-2) \\
<0.001 * *\end{array}$ & \\
\hline $\mathbf{P}(\mathbf{F})$ & $<0.001 * *$ & $<0.001 * *$ & \\
\hline
\end{tabular}

* significant

In terms of postoperative complications, there was a statistically significant difference between the two groups analyzed. Non-complicated were 23 in obstructed hernia versus 4 in strangulated hernia (Table 7).

Table (7) Comparison between types of complicated hernia regarding postoperative complications

\begin{tabular}{|l|c|c|c|}
\hline Parameter & \multicolumn{2}{|c|}{ Complicated hernia } & \multirow{2}{*}{ P } \\
\hline $\begin{array}{l}\text { Postoperative } \\
\text { complications }\end{array}$ & $\begin{array}{c}\text { Obstructed } \\
\mathbf{N}=\mathbf{3 0}\end{array}$ & $\begin{array}{c}\text { Strangulated } \\
\mathbf{N}=\mathbf{1 0}\end{array}$ & \\
\hline No & $23(76.7)$ & $4(40)$ & \multirow{2}{*}{$\mathbf{0 . 0 0 1}$} \\
\hline Wound infection & $0(0)$ & $5(50)$ & \\
\hline Seroma & $6(20)$ & $0(0)$ & \\
\hline Scrotal edema & $1(3.3)$ & $1(10)$ & \\
\hline
\end{tabular}

\section{DISCUSSION}

It is typical for mesh-based procedures to be used to treat inguinal hernias. As a result of its prevalence, it is still a significant medical issue. Groin hernias are most often caused by male gender and advanced age, additionally groin hernias' family history. In addition to smoking and chronic obstructive pulmonary disease (COPD), there are a number of other contributing factors ${ }^{(7)}$.

Due to the fact that until recently, inguinal hernia surgery was suggested, there is still no medical recommendation on how to treat this ailment. Reason behind these recommendations is feared complication's risks like as; incarceration or the strangulations ${ }^{(8)}$.

The inexpensive cost of Desarda's method is a major advantage. As a result, a number of published studies have lately shown an interest in the technique because the data available to judge the results of this technique is fewer due to centers usually adopting established and trustworthy techniques ${ }^{(4)}$.
Patient ages varied from 18 to 86 years, with a mean of 47.67 years in our study. About $68 \%$ of the studied patients had no comorbidity. Diabetes, hypertension, and both of them prevailed in $7.5 \%$, $12.5 \%$ and $5 \%$ of patients respectively. Krishna et al. ${ }^{(9)}$ found that the entire average age was $49 \pm 14.9$ years. A patient's age ranged from 18 to 82 , and the mean age of those in groups I and II was $47.8 \pm 16.0$ years and $51.3 \pm 13.8$ years, respectively. In terms of age distribution, there was no statistically significant difference between the two groups $(\mathrm{p}=0.414)$.

In our study, twenty-seven $(67.5 \%)$ of the studied patients had no postoperative complications. Wound infection, seroma and scrotal edema occurred in $12.5 \%, 15 \%$ and $2.5 \%$ of patients respectively. Abbas et al. (10) reported at least twenty patients have experienced some sort of postoperative problem Pneumonias (lobar or bronchopneumonia) accounted for $20 \%$ of cases, as did sepsis syndrome (14\%), and infections of local wounds (6 percent). Roy et al. ${ }^{(11)}$ also found comparable results, 184 cases were treated 
with Desarda technique, out of them 12 cases had postoperative complications, particularly 7 cases had developed wound infection, seroma was in 3 cases and hematoma in 2 cases, furthermore they reported that one patient had developed recurrent inguinal hernia.

Our study confirmed statistically a significant decrease in postoperative VAS pain score over time which decreased from 4.275 two hours postoperatively to 1 in the first postoperative week. Gurgenidze and Datuashvili (12) found the VAS (Mean \pm SD) postoperative pain on day one was $31.27 \pm 0.86$. Day 3 saw a considerable decrease in pain, with the exception of one patient whose small intestine was also removed at the same time, who reported moderate pain. This procedure resulted in no more than 15 days of discomfort for any of the patients. Opioid analgesics weren't even needed once.

The Visual Analogue Scale (VAS) was used by Khairy et al. ${ }^{(4)}$ to assess postoperative pain. On the second postoperative day, the mean VAS score was 3.12. One-week postoperatively, mean VAS was 1.28 and mean VAS at one month was 0.12 . Only 12 patients had pain at the end of one month. The impact of pain was obvious on the patient's return to them daily activity and work.

Regarding postoperative VAS score, there was statistically significant difference between obstructed and strangulated hernia (significantly higher among strangulated hernia). On comparing percent change in VAS over time, VAS in obstructed hernia decreased by $303.57 \%$ while it decreased by $377.78 \%$ in strangulated hernia with a statistically non-significant difference.

As far as the above criteria go, Desarda appears to meet them. In this procedure, there is no usage of weaker muscles or transversalis fascia, and no difficult dissection or suturing is required. The method is simple to master. The author states that his procedure has a complication rate of $1.8 \%$ and a recurrence rate of $0.2 \%$ that is superior or equal to that of Shouldice and Lichtenstein repairs ${ }^{(\mathbf{1 3})}$.

Khairy et al. ${ }^{(4)}$ concluded that there are no prosthetics or difficult inguinal canal dissections required to perform Desarda repair. Priority is given to young patients, diseased surgery sites, and those with financial constraints, as well as those who have previously rejected mesh or those who have a history of mesh rejection elsewhere.

\section{CONCLUSION}

Our study showed that the results after herniorrhaphy by Desarda for surgical treatment of inguinal hernia are good. According to our research, the Desarda technique appears to be a viable alternative to current practices. There are no problems or hernia recurrences as a result of this procedure, which is rapid, uncomplicated, and easy to learn and conduct.
This procedure can be done as an outpatient procedure in one day. In this procedure, the mesh is not employed, thus there is no risk of mesh infection. As a result, it can be used properly. Additionally, diabetic people might be freed from the dread of mesh infection by using this method. Use in young patients, in polluted surgical fields, in the presence of limited funding or when patients refuse or have already rejected mesh in another place are all indications for the Desarda technique's use. Hernia repair could become a gold standard if Desarda repair is developed further.

Financial support and sponsorship: Nil. Conflict of interest: Nil.

\section{REFERENCES}

1. Ayandipo O, Afuwape O, Irabor D et al. (2015): Adult abdominal wall hernia in Ibadan. Annals of Ibadan Postgraduate Medicine, 13(2): 94-99.

2. Jenkins J, O'Dwyer P (2008): Inguinal hernias. In BMJ., 336: 269-272.

3. Wilson $\mathbf{N}$ (2002): Femoral hernia. In Key Topics in General Surgery. CRC Press. Pp. 91-92.

4. Khairy M, Madbouly A, Sharaf M (2020): Evaluation of Desarda technique in inguinal herniorrhaphy. AlAzhar International Medical Journal, 20: 1-5.

5. Khan H, Ramesh B, Bobburi V (2020): Tension free, mesh free inguinal hernia repair: a prospective study of Desarda's technique. International Surgery Journal, 7(4): 1116-22.

6. Desarda M (2003): Surgical physiology of inguinal hernia repair - A study of 200 cases. BMC Surgery, 3: $1-7$.

7. Koivusalo A (2018): Inguinal hernia. In Rickham's neonatal surgery. Springer Singapore. Pp. 637-650.

8. Bittner R, Arregui M, Bisgaard T et al. (2011): Guidelines for laparoscopic (TAPP) and endoscopic (TEP) treatment of inguinal hernia [International Endohernia Society (IEHS)]. Surgical Endoscopy, 25(9): 2773-2843.

9. Krishna A, Misra M, Bansal V et al. (2012): Laparoscopic inguinal hernia repair: Transabdominal preperitoneal (TAPP) versus totally extraperitoneal (TEP) approach: A prospective randomized controlled trial. Surgical Endoscopy, 26(3): 639-649.

10. Abbas Z, Bhat S, Koul M et al. (2015): Desarda's no mesh repair versus Lichtenstein's open mesh repair of inguinal hernia: a comparative study. Journal of Evolution of Medical and Dental Sciences, 4(77): 13279-83.

11. Roy B, Hanifa M, Naher S et al. (2016): Outcome of Desarda repair in inguinal hernia: a study in northern part of Bangladesh. Int J Med Sci Public Health, 5:521524

12.Gurgenidze M, Datuashvili G (2018): Desarda technique for inguinal hernia repair. Georgian Med News, 7(10): 280-281.

13. Gedam B, Bansod P, Kale V et al. (2017): A comparative study of Desarda's technique with Lichtenstein mesh repair in treatment of inguinal hernia: A prospective cohort study. International Journal of Surgery, 39: 150-155. 